\title{
Anthropometric evaluation of ratio between extremity length and body length in basketball player adolescents
}

\author{
Korkmaz M.F. ${ }^{1 \mathrm{ABCDE}}$, Cetin A. ${ }^{2 \mathrm{BCD}}$, Bozduman O. ${ }^{3 \mathrm{CD}}$ \\ ${ }^{1}$ Department of Orthopaedics and Traumatology, Istanbul Medeniyet University School of Medicine, Turkey \\ ${ }^{2}$ Deparment of Anatomy, Inonu University School of Medicine Malatya, Turkey \\ ${ }^{3}$ Department of Orthopaedics and Traumatology, Afyonkarahisar State Hospital, Turkey
}

Authors' contributions: A - Study design; B - Data collection; C - Statistical analysis; D - Manuscript Preparation; E - Funds Collection.

\begin{abstract}
Purpose: $\quad$ To determine whether the limb length-to-body ratio in young basketball players (15-18 years) is different in comparison to those who do not play basketball, and to contribute to the hypothesis that those with which body type can be more successful in basketball.

Material: $\quad$ The measurements were performed on 42 individuals ( 29 boys, 13 girls) who have played basketball for at least three years and 41 individuals (31 boys, 10 girls) who did not play basketball. A standard form was prepared for these measurements and the measurements were made according to this form. The data were summarized using mean and standard deviation values, and their accordance with normal distribution was evaluated with the Shapiro-Wilk test. The t-test was used for evaluating the independent samples. Values of $p<0.05$ were considered significant. The measurements were performed using a tape measure.

Results: $\quad$ As a result of the measurements, the height/fa (forearm) ratio was 7.09 in non-basketball players and 6.71 in basketball players. The height/hl (hand length) ratio was 10.0 in non-basketball players and 9.06 in basketball players. The height /III (lower limb length) ratio was 1.86 in non-basketball players and 1.73 in basketball players. The height /tl (thigh length) ratio was 3.28 in non-basketball players and 3.41 in basketball players. According to our findings, the ratio of forearm, hand, thigh and leg to body were increased in basketball players. There was no significant difference in terms of gender.

Conclusions: $\quad$ Athletes possess anthropological and physiological characteristics specific to the sport in which they participate. In terms of limb length, there was an anthropometric difference between the young population who played basketball and the normal population.

Keywords: $\quad$ basketball, morphometry, anthropometric, limb.
\end{abstract}

\section{Introduction}

Humans have various body types from an anthropological perspective. These types are defined in anthropological terms such as endomorph, mesomorph and ectomorph. In general, people choose or are directed to sports that are suitable for their body type. This increases the success of people in the related sport. Often, there are anthropological and physiological differences between individuals who participate in sports and those from the normal population [1-3].

There are many articles on basketball players. However, we failed to come across any anthropometric study in the literature similar to ours. The most similar study was performed in 1991 by a researcher named Bale [4]. This researcher grouped the basketball players according to their positions on the field and reported that the midfield players had longer limbs than the defenders.

The comparison of the anthropometric measurements of athletes is of great importance in modern sports and is still being studied by this sport science [5].

The literature holds this type of studies in various sports branches. Sedeaud et al. reported about the physical differences between the normal population and individuals that played baseball, football, ice hockey and basketball. In the same study, the authors reported that the

(c) Korkmaz M.F., Cetin A., Bozduman O., 2020

doi:10.15561/26649837.2020.0304 top scorers in the NBA were over 2 meters $[6,7]$.

Gabbett et al. performed anthropometric measurements on young volleyball players from the first-tier, second-tier and amateur leagues. The authors showed that the physical and anthropometric features (such as height, skinfold thickness, lower body muscle strength and agility) of the players increased according to the level of the league [8].

Anthropometric studies comparing different sports branches can also be found in the literature. Bayios et al. took the anthropometric measurements of 518 players from the Greek women's first basketball, volleyball and handball leagues. The authors concluded that volleyball players comprised the tallest of the three groups and that basketball players were taller and leaner than the handball players [9].

Studies on extremity profiles have shed light on the literature [9-11].

In a study on body profiles of professional soccer players, Snow et al. reported different extremity profiles for those who played soccer in comparison to the individuals from the normal population [12].

Pelin et al. compared the athletes who played American football, basketball, volleyball and soccer among themselves and with non-player individuals in terms of anthropometric features. The authors observed longer lower limbs in volleyball and basketball players, an increased biiliac width in American football players, 
and a smaller structure in soccer players [5].

In our study, we tried to present the anthropometric differences in terms of limb length between the young population who played basketball and the normal population.

\section{Materials and Methods}

Participants.

Attention was paid to the include subjects who have played basketball for at least three years. The measurements were performed on 42 individuals (29 boys, 13 girls) who played basketball and 41 individuals (31 boys, 10 girls) who did not play basketball.

Research Design.

A standard form was prepared for these measurements and the measurements were made according to this form.

The following parameters were used during the measurements:

- Upper limb length (ULL): The distance between the tips of the shoulder and the middle finger $(\mathrm{cm})$;

- Arm length (AL): The distance between the shoulder tip and the midline of the elbow joint $(\mathrm{cm})$;

- Forearm length (FAL): The distance between the midline of the elbow joint and the wrist $(\mathrm{cm})$;

- Hand length (HL): The distance between the wrist midline and the middle fingertip $(\mathrm{cm})$;

- Lower limb length (LLL): The distance between the anterior superior iliac spine and the ground $(\mathrm{cm})$;

- Thigh length (TL): The distance between the anterior superior iliac spine and the mid-knee joint $(\mathrm{cm})$;

- $\quad$ Leg length (BU): The distance between the mid-knee joint and the ground $(\mathrm{cm})$;

Statistical Analysis.

The data were summarized using mean and standard deviation values, and their accordance with normal distribution was evaluated with the Shapiro-Wilk test. The t-test was used for evaluating the independent samples. Values of $\mathrm{p}<0.05$ were considered significant.
The measurements were performed using a tape measure.

\section{Results}

In order to standardize the measurements, the ratios to the subject's height were considered in the assessments. All ratios and their statistical evaluations are presented in Table 1.

While the height/ULL ratio was 2.28 in non-basketball players, it was found 2.26 in basketball players. ULL was greater in basketball players $(\mathrm{p}=0.140)$. However, no significant difference was observed regarding the upper limb length.

While the height/AL ratio was 5.75 in non-basketball players, it was found 5.57 in basketball players. Basketball players had a greater AL $(\mathrm{p}=0.082)$. However, no significant difference was observed regarding the arm length.

The height /FAL ratio was 7.09 in non-basketball players and 6.71 in basketball players. Forearm length was higher in basketball players and the difference was found to be significant $(\mathrm{p}=0.001)$.

The length/HL (hand length) ratio was 10.0 in nonbasketball players and 9.06 in basketball players. Hand length was also found to have increased significantly in basketball players $(\mathrm{p}=0.001)$.

The height/LLL (lower limb length) ratio was 1.86 in basketball players and 1.73 in basketball players. Lower extremity length was also found to have increased significantly in basketball players $(\mathrm{p}=0.004)$.

The height/TL (thigh length) ratio was 3.28 in nonbasketball players and 3.41 in basketball players. Thigh length was also found to have increased significantly in basketball players $(p=0.002)$.

The height/LL (leg length) ratio was 3.86 in nonbasketball players and 3.51 in basketball players. Leg length was also found to have increased significantly in basketball players $(p=0.0001)$.

Table 1. The height-to-limb length ratios in basketball and non-basketball players.

\begin{tabular}{|c|c|c|c|c|}
\hline Group & $\mathbf{n}$ & Mean & St deviation & $P$ value \\
\hline Height/ULL Non-basketball player & 41 & 2.28 & 0.06 & \multirow{2}{*}{0.140} \\
\hline Basketball player & 42 & 2.26 & 0.06 & \\
\hline Height/AL Non-basketball player & 41 & 5.75 & 0.42 & \multirow{2}{*}{0.082} \\
\hline Basketball player & 42 & 5.57 & 0.50 & \\
\hline Height/FAL Non-basketball player & 41 & 7.09 & 0.48 & \multirow{2}{*}{0.001} \\
\hline Basketball player & 42 & 6.71 & 0.53 & \\
\hline Height/HL Non-basketball player & 41 & 10.00 & 1.53 & \multirow{2}{*}{0.001} \\
\hline Basketball player & 42 & 9.06 & 0.72 & \\
\hline Height/LLL Non-basketball player & 41 & 1.86 & 0.25 & \multirow{2}{*}{0.004} \\
\hline Basketball player & 42 & 1.73 & 0.11 & \\
\hline Height/TL Non-basketball player & 41 & 3.41 & 0.21 & \multirow{2}{*}{0.002} \\
\hline Basketball player & 42 & 3.28 & 0.16 & \\
\hline Height/LL Non-basketball player & 41 & 3.86 & 0.23 & \multirow{2}{*}{0.0001} \\
\hline Basketball player & 42 & 3.51 & 0.27 & \\
\hline
\end{tabular}




\section{Discussion}

Several comparative anthropological and physiological studies on various sports exist in the literature [13]. Needless to say, these studies help us to learn the anthropological and physiological characteristics of the individuals who are active in any sport and help those who want to participate in sports to make their choices. Sanchez-Munoz et al. compared the anthropometric characteristics of male and female tennis players who played in the premier and amateur leagues. There was no significant difference in terms of height and weight between the male players in the premier and amateur leagues, however, a difference was detected in female players [13].

Some studies in the literature have compared the athletes in terms of anthropometric and physiological aspects according to gender, age and the zones they played. For example, Gabbett reported about the anthropometric and physiological characteristics of the rugby league players (Youth League and Young Women's League) in two studies. There was no significant different in terms of anthropometric and physiological differences between the selected and unselected players in the Young Women's premier rugby league, whereas a significant difference was found between the offensive and defensive players in terms of body mass, skinfold thickness and acceleration $[14,15]$. In another study, Bale grouped the young female basketball players who played in the first league according to their positions on the field, performed anthropometric measurements, and found that midfield players had longer limbs, wider hips, and more muscles [4]. Ostojic et al. compared the physical and physiological measurements of the basketball players who played in the first league. The researchers found that the defenders were older and experienced, the midfielders were taller and heavier, and the offensive players were taller and heavier than the defenders [16].
A study comparing various anthropometric measurements in terms of age in the same sport was conducted by Karalejic et al. The authors performed and compared anthropometric measurements of basketball players aged 12 to 14 years, and noted that all measurements other than the sitting height-to-standing height ratio and body mass index were different [17].

As in our study, athletes have been compared with the normal population in several studies [18-20]. In our study, basketball players and non-basketball players were compared in terms of some anthropometric values. In our study where we compared the individuals who were 15 to 18 years of age and played basketball with those who did not play basketball, the hand, forearm, lower limb, thigh and leg lengths were found significantly increased in basketball players.

\section{Conclusion}

Athletes possess anthropological and physiological characteristics specific to the sport in which they participate. There was an anthropometric difference between the limb lengths of the young population that played basketball and those of the normal population. If this study is to be performed with the participation of more subjects and the inclusion of other parameters, we believe that it will provide more detailed information to those who are interested in basketball.

\section{Source of Funding}

No financial or material support was received in conducting this research or in preparing this manuscript.

\section{Conflicts of interest}

The authors declare no conflict of interest.

\section{References}

1. Van Gent M, Spamer E. Comparisons of positional groups in terms of anthropometric, rugby-specific skills, physical and motor components among U 13, U 16, U 18, and U 19 elite rugby players. Kinesiology. 2005; 37: 50-63.

2. Round J, Jones D, Honour J, Nevill A. Hormonal factors in the development of differences in strength between boys and girls during adolescence: a longitudinal study. Annals of Human Biology. 1999; 26(1): 49-62. https://doi.org/10.1080/030144699282976

3. Greene J, McGuine T, Leverson G, Best T. Anthropometric and performance measures for high school basketball players. Journal of Athletic Training. 1988; 33(3): 229-232.

4. Bale P. Anthropometric, body composition and performance variables of young elite female basketball players. $J$ Sports Med Phys Fitness. 199; 31(2):173-7.

5. Pelin C. Kürkçüoğlu A, Ozener B, Yazici AC. Anthropometric characteristic of young Turkish male athletes. Coll Antropol. 2009; 33(4): 1057-63.

6. SedeaudA,MarcA,SchipmanJ,SchaalK,DanialM, Guillaume M, Berthelot G, Toussaint JF. Secular trend: morphology and performance. J Sports Sci. 2014; 32(12):1146-54. https://doi.org/10.1080/02640414.2014.88984

7. Sedeaud A, Vidalin H, Tafflet M, Marc A, Toussaint JF. Rugby morphologies: "Bigger and taller", reflects an early directional selection. The Journal of Sports Medicine and Physical Fitness, 2013; 53(2), 185-191.

8. Gabbett T, Georgieff B. Physiological and anthropometric characteristics of Australian junior national, state, and novice volleyball players. J Strength Con Res. 2007; 21(3):902-8. https://doi.org/10.1519/00124278-200708000-00042

9. Bayios IA, Bergeles NK, Apostolidis NG, Noutsos KS, Koskolou MD. Anthropometric, body composition and somatotype differences of Greek elite female basketball, volleyball and handball players. $J$ Sports Med Phys Fitness. 2006; 46(2):271-80.

10.Simenz CJ, Dugan CA, Ebben WP. Strength and conditioning practices of National Basketball Association strength and conditioning coaches. Journal of Strength and Conditioning Research/National Strength, Conditioning Association. 2005; 19(3): 495-504. https://doi.org/10.1519/00124278-200508000-00003

11. YousafzaiA, Filteau S, Wirz S, Cole T. Comparison of armspan, arm length and tibia length as predictors of actual height of 
disabled and nondisabled children in Dharavi, Mumbai, India. European Journal of Clinical Nutrition. 2003; 57: 1230-1234. https://doi.org/10.1038/sj.ejen.1601705

12.Snow T, Millard-Stafford M, Rosskopf L. Body composition profile of NFL players. Journal of Strength and Conditioning Research/National Strength, Conditioning Association. 1998; 12: 146-149. https://doi.org/10.1519/00124278-199808000-00003

13.Sanchez-Munoz C, Sanz D, Zabala M. Anthropometric characteristics, body composition and somatotype of elite junior tennis players. Br J Sports Med. 2007; 41(11):793-9. https://doi.org/10.1136/bjsm.2007.037119

14.Gabbett TJ. Physiological and anthropometric characteristic of elite women rugby league players. J Strength Cond Res. 2007; 21(3):875-81. https://doi.org/10.1519/00124278-200708000-00038

15.Gabbett TJ.A comparison of physiological and anthropometric characteristics among playing positions in junior rugby league players. $B r J$ Sports Med. 2005; 39(9):675-80. https://doi.org/10.1136/bjsm.2005.018275

16.Ostojic SM, Mazic S, Dikic N. Profiling in basketball: physical and physiological characteristics of elite players. J Strength Cond Res. 2006; 20(4):740-4. https://doi.org/10.1519/00124278-200611000-00003

17.Karalejic M, Jakovljevic S, Macura M. Anthropometric characteristics and technical skills of 12 and 14 year old basketball players. J Sports Med Phys Fitness. 2011; 51(1):103-10.

18.Ackland TR, Schreiner AB, Kerr DA. Absolute size and proportionality characteristics of World Championship female basketball players. Journal of Sports Sciences. 1997; 15(5): 485-490. https://doi.org/10.1080/026404197367128

19.Hoare DG. Predicting success in junior elite basketball players - The contribution of anthropometic and physiological attributes. Journal of Science and Medicine in Sport/Sports Medicine Australia, 2000;3(4): 391-405. https://doi.org/10.1016/S1440-2440(00)80006-7

20.Norton K, Olds T. Morphological evolution of athletes over the 20th century: Causes and consequences. Sports Medicine (Auckland, N.Z.). 2001; 31(11): 763-783. https://doi.org/10.2165/00007256-200131110-00001

\section{Information about the authors:}

Korkmaz M.F.; (Corresponding author); MD, Associate Professor; http://orcid.org/0000-0001-7498-6763; dr_mfatih@yahoo. com; Department of Orthopedics and Traumatology, Faculty of Medicine, Istanbul Medeniyet University; Istanbul, Turkey.

Cetin A.; Assistant Professor; http://orcid.org/0000-0002-4645-2059; aymelek.cetin@inonu.edu.tr; Deparment of Anatomy, Faculty of Medicine, Inonu University; Malatya, Turkey.

Bozduman 0.; Medical doctor; http://orcid.org/0000-0002-3874-633X; omerbozduman@gmail.com; Department of Orthopaedics and Traumatology, Afyonkarahisar State Hospital; Afyon, Turkey.

Cite this article as:

Korkmaz MF, Cetin A, Bozduman O. Anthropometric evaluation of ratio between extremity length and body length in basketball player adolescents.. Pedagogy of physical culture and sports, 2020;24(3):125-128.

https://doi.org/10.15561/26649837.2020.0304

This is an Open Access article distributed under the terms of the Creative Commons Attribution License, which permits unrestricted use, distribution, and reproduction in any medium, provided the original work is properly cited (http://creativecommons.org/licenses/by/4.0/deed.en).

Received: 17.11.2019

Accepted: 16.12.2019; Published: 05.01.2020 